\title{
The Correlation Between Neutrophil Lymphocyte Ratio with Disease Activity in Systemic Lupus Erythematosus
}

\author{
G Kambayana ${ }^{1}$, I Gusti Agung Friskha Surya Putra ${ }^{2}$, Pande Ketut Kurniari ${ }^{1}$, Tjokorda Raka Putra ${ }^{1}$
}

${ }^{1}$ Rheumatology Division, Department of Internal Medicine, Faculty of Medicine, University of Udayana, Sanglah Hospital

2 Department of Internal Medicine, Faculty of Medicine, University of Udayana, Sanglah Hospital

\section{A R T I C L E I N F O}

\section{Keywords:}

Systemic Lupus Erythematosus, Neutrophil to Lymphocyte Ratio Mex-SLEDAI

\section{Corresponding author: \\ G Kambayana \\ E-mail address: gede_kambayana@yahoo.com}

All authors have reviewed and approved the final version of the manuscript.

https://doi.org/10.37275/IJR.v10i1.1

\begin{abstract}
A B S T R A C T
Background. Systemic Lupus Erythematosus (SLE) is an Autoimmune inflammatory disease that is systemic and chronic inflammation with heterogeneous of history, clinical manifestations, and prognosis. The disease activity of SLE has been proven as a predictor of organ damage and death by evidenced of inflammatory markers involved in this disease. Neutrophil to Lymphocyte Ratio (NLR) is useful for estimating the activity of autoimmune disease and inflammation. It is easily obtained from blood test and relatively cheap. It could be used as new biomarker to assess inflammatory response or activity of SLE. This study aimed to determine the relationship between NRL and Disease Activity based on Mex-SLEDAI in patients SLE. Methods. This was an analytic study with cross sectional design. It started from November 2016 until March 2017. The target population is adult with SLE (aged 18 years or older) in Bali, according to the 1997 American College of Rheumatology criteria. Patients with several comorbid diseases and other illness were excluded. Mex-SLEDAI and blood sampling used in this study. Result. Total sample in this study was 54 patients with median age of 28.5 years, with mostly female $(85.2 \%)$. A positive correlation obtained between NLR with disease activity on SLE $(r=0.399 \mathrm{p}=0.003)$. The scatter plot showed a correlation between NRL with Mex-SLEDAI. Conclusion. There was positive correlation between NLR and disease activity of the SLE, in which the higher of the disease activity/Mex-SLEDAI will be followed by the increase of NLR.
\end{abstract}

\section{Introduction}

Systemic Erythematosus Lupus (SLE) is a systemic autoimmune inflammatory disease, chronic with unknown etiopathogenesis, clinical manifestations, disease course and very diverse prognosis. ${ }^{1,2}$ Disease activity in SLE has been independently proven as a predictor of organ damage and death, as evidenced by various inflammatory markers involved in the pathogenesis of SLE disease. It includes C-reactive Protein (CRP), that was evidenced in the study of Toloza et al., suggested the relationship between high CRP values and organ damage and was confirmed through an index scoring system, thus concluded that increased CRP values were associated with systemic inflammation and organ damage rates. ${ }^{1}$
Neutrophil Lymphocyte Ratio (NLR) is used as a marker of inflammation. Neutrophil Lymphocyte Ratio is calculated as the absolute number of neutrophils divided by the absolute number of lymphocytes. Neutrophil Lymphocyte Ratio is useful for estimating the activity of autoimmune and inflammatory diseases. It is an inflammatory marker in systemic inflammation that does not require expensive cost and easy to do, however its mechanism for SLE is still not fully understood. ${ }^{3,4}$

In a meta-analysis by Lee et al., it was shown that NLR and Lymphocyte Platelet Ratio (LPR) were significantly higher in SLE than in the control group and correlated with lupus activity measured according 
to SLEDAI. This large correlation may indicate NLR and LPR associated with cytokines or inflammatory products from the high SLE activity. NLR is an indicator of inflammation that is easily obtained from routine blood tests and does not require large costs, easily available and measured, so it is quite effective as a new biomarker to assess the inflammatory response or activity of lupus. ${ }^{3}$

The purpose of this study was to assess the correlation between the ratio of neutrophils / lymphocytes and SLE disease activities that were treated as outpatient or inpatient at Sanglah Hospital Denpasar.

\section{Research Methods}

\section{Study Design}

This was an analytical study with a cross-sectional design. The target population was adult with SLE (aged 18 years or older) in Bali. Accessible population consists of outpatients / inpatients at Sanglah General Hospital. Inclusion criteria were all SLE adult patients on treatment as outpatient and inpatient at Sanglah General Hospital in November 2016 to March 2017. Exclusion criteria included SLE with sepsis, neuropsychiatric SLE / NPSLE, lupus nephritic, with severe comorbid disease (chronic heart failure, chronic kidney disease, and malignancy), Diabetes mellitus and hypertension. The total sample size obtained was 54 samples diagnosed with SLE based on the 1997 American College of Rheumatology criteria. The study sample was obtained consecutively. Each sample was then assessed for disease activity based on MEXSLEDAI and blood samples were taken for routine blood tests. Data relating to the degree of inflammation and the ratio of neutrophils / lymphocytes collected, then analyzed.

The collected data was analyzed using the SSPS 22.0 program. Statistical analysis in this study used descriptive tests to determine the characteristics of the subject and use the Spearman correlation test because the data were not normally distributed.

\section{Statistical Analysis}

Descriptive data about subject characteristics was presented in the form of mean \pm standard deviation (for data that are normally distributed) and median values (minimum-maximum values) for data that are not normally distributed. For the correlation analysis, we employed Pearson correlation analysis if the data distributed normally, or Spearman correlation of the data were not distributed normally. All data were analyzed using SPSS 22.0

\section{Results}

The subjects in this study were 54 patients with a median age of 28.5 years. Most subjects were female $(85.2 \%)$. Other subjects' characteristics depicted in table 1.

From the correlation analysis. the results of analysis showed a positive correlation between the ratio of neutrophils / lymphocytes with disease activity in SLE (table 2 and figure 1)

Table 1. Overview of the study subject characteristics $(n=54)$

\begin{tabular}{lll}
\hline Characteristics & $\begin{array}{l}\text { Median - Range } \\
\text { (minimum-maximum) }\end{array}$ & Value
\end{tabular}

\begin{tabular}{lll}
\hline Age (year old) & 28.5 & $(14-65)$ \\
\hline Gender & & \\
Male & 8 & 14.8 \\
Female & 46 & 85.2 \\
\hline BMI & & $22.2 \pm 2.925$ \\
\hline
\end{tabular}




\begin{tabular}{lll}
\hline $\begin{array}{l}\text { Type of treatment } \\
\text { Corticosteroid duration }\end{array}$ & & $113 \pm 24.2$ \\
(months) & $18(3-114)$ & \\
$\quad$ Corticosteroid dosage $(\mathrm{mg})$ & $4(4-48)$ & $18(3-114)$ \\
Illness duration (months) & $0(0-10)$ \\
MEX-SLEDAI & $2.91(0.77-16.3)$ \\
Neutrophils lymphocytes ratio & \\
\hline
\end{tabular}

Table 2. Result of Spearman correlation test

\begin{tabular}{lll}
\hline & & $\begin{array}{l}\text { Neutrophils/lymphocytes } \\
\text { ratio }\end{array}$ \\
\hline Disease activity & $\mathrm{r}$ & 0.399 \\
(MEX-SLEDAI) & $\mathrm{p}$ & 0.003 \\
& $\mathrm{n}$ & 54 \\
\hline
\end{tabular}

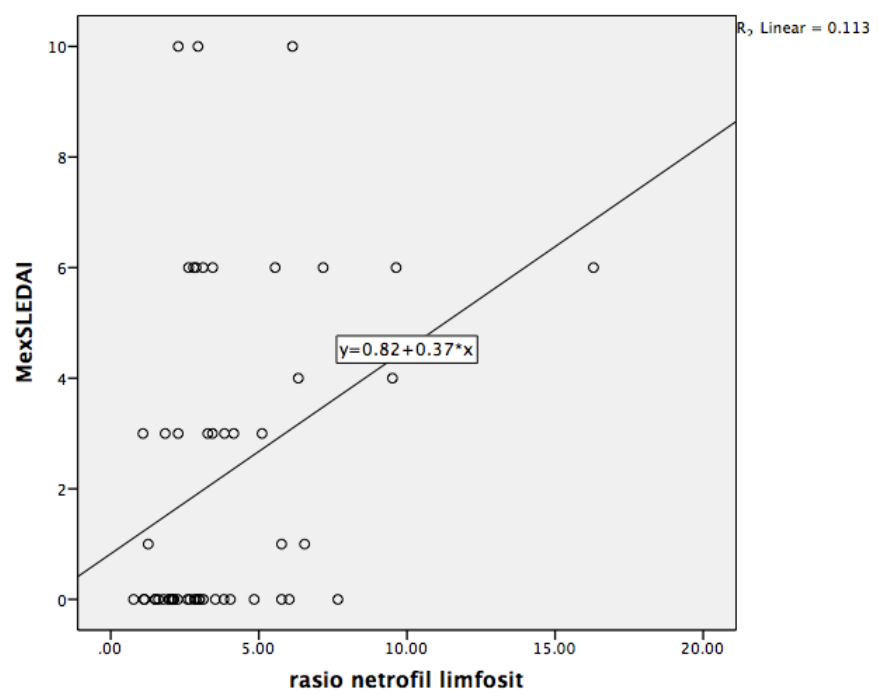

Figure 1. Scatter plot showed correlation between neutrophils/lymphocytes ratio with Mex-SLEDAI

\section{DISCUSSION}

This study found a correlation between the ratio of neutrophils / lymphocytes and SLE disease activity, in which the higher the disease / Mex-SLEDAI activity, the ratio of neutrophils / lymphocytes also got higher. This study is consistent with previous studies such as the cohort study by Lee et al., which showed that NLR and LPR were significantly higher in SLE than in the control group and correlated with lupus activity measured according to SLEDAI. ${ }^{3}$ An increase in NLR is associated with an increase in cytokines and the inflammatory process in SLE. ${ }^{3}$

Another study conducted by Gunawan et al. in 2017, involving seventy lupus patients studied at RSUD Dr. Soetomo Surabaya, showed that there was a relationship between disease activity, which calculated according to SLAM, and an increase in NLR, with $\mathrm{r}=$ 0.249 and $p<0.038$. In the study, it was concluded that NLR was associated with the activity of lupus, the higher activity of lupus was positively correlated with an increase in the neutrophil / lymphocyte ratio. ${ }^{4}$

Lupus nephritis is characterized by immune complex deposition in kidney, which can activate the complement system then the inflammatory cells / mediators such as neutrophils, monocytes, eosinophils and $\mathrm{T}$ lymphocytes. It can stimulate cell phagocytosis and release reactive oxygen species that can damage the body tissues.5,6 This theoretical basis were the mechanism behind the relationship of inflammatory marker and disease activity of SLE.

The study carried out by Li et al. 2015 also examined the role of neutrophils / lymphocytes in the 
SLE population. It was conducted in 228 lupus patients and aimed to evaluate the role of NLR in lupus patients with lupus nephritis and lupus patients without complications of lupus nephritis. The results showed higher NLR in lupus patients with complications of lupus nephritis compared with patients with no complications $(\mathrm{SLE}=4.263 .38, \mathrm{LN}=7.216 .01, \mathrm{P}$ $<0.001)$. The conclusion of this study is that NLR independently associated with the activity of SLE disease and can be a promising marker that reflects renal involvement in SLE patients. ${ }^{7}$

Systemic lupus erythematosus is a chronic inflammatory process that involves inflammatory cells such as neutrophils, monocytes, T lymphocytes and is also related to the infiltration process of the complement system..$^{8,9,10}$

\section{CONCLUSION}

Neutrophil Lymphocyte Ratio (NLR) has a positive correlation with disease activity in SLE patients who treated at Sanglah Hospital. This study is expected to expand our insight into the role of NLR on the severity of SLE disease activity so we can provide the appropriate treatment.

\section{REFERENCES}

1. Toloza SM, Uribe AG, McGwin G, Alarcon GS, Fessler BJ. Systemic lupus erythematosus in a multiethnic US cohort (LUMINA) XXIII. Baseline predictors of vascular event. Arthritis Rheum. 2004;50: 3947-3957.

2. Isbagio H, Kasjmir YI, Setyohadi B, Suarjana N. Dalam: Sudoyo AW, Setiyohadi B, Alwi I,
Simadibrata M, Setiati S, penyunting. Lupus Eritematosus Sistemik. Buku Ajar Ilmu Penyakit Dalam Edisi Kelima. Jakarta: Internal Publishing. 2009: 2565-2577.

3. Lee YH, Song GG. Association of Neutrophil to Lymphocyte Ratio, Platelet to Lymphocyte Ratio, and Mean Platelet Volume with Systemic Lupus Erythematosus Disease Activity: A Meta-analysis. Journal of Rheumatic Diseases. 2017;24(5): 279286.

4. Gunawan H, Awalia A, Soeroso J. 159 Neutrophil to lymphocyte ratio and systemic lupus erythematosus: a new parameter for disease activity assessment?. BMJ journal. 2017;4(1): A73-A74.

5. Cook HT, Botto M. Mechanisms of Disease: the complement system and the pathogenesis of systemic lupus erythematosus. Nat Clin Pract Rheumatol. 2016: 2: 330-337.

6. Koscielska K, Bartoskezk D, Myszka M, Zabriska $\mathrm{M}$, Klinger M. The Complement cascade and renal disease. Arch Immunol Ther Exp. 2014;62: 47-57.

7. Li L, Xia Y, Chen C, Cheng P, Peng C. Neutrophillymphocyte ratio in systemic lupus erythematosus disease: a retrospective study. Int $\mathrm{J}$ Clin Med. 2015;8(7):11026-11031.

8. Hahn BH, McMahon MA, Wilkinson A, Wallace WD, Daikh DI, Singh K. et al. American College of Rheumatology guidelines for screening case, definition, treatment and management of lupus nefritis. Arthritis Care Res. 2012;64: 797-808.

9. El Minshawy O, El-Bassuoni E. Albuminuria prediction of kidney function outcome in kidney transplant recipients. Saudi J Kidney Dis Transpl. 2015;26: 227-231.

10. Kahlenberg JM, Kaplan MJ. The inflammation and lupus lupus: another innate immune mechanism contributing to disease pathogenesis. Curr Opin Rheumatol. 2014;26: 475-481. 